www.jmscr.igmpublication.org Impact Factor 5.244

Index Copernicus Value: 83.27

ISSN (e)-2347-176x ISSN (p) 2455-0450

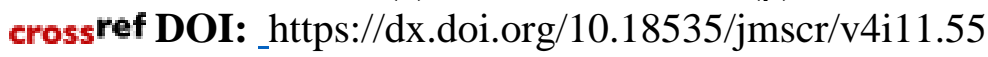

Journal Of Medical Science And Clinical Research

\title{
Socio-Demographic and Health Related Correlates of Loneliness in Elderly
}

\author{
Authors \\ Raut Nitin B ${ }^{1}$, Singh Shipra ${ }^{2}$, Subramanyam Alka $A^{3}$, Pinto Charles ${ }^{4}$ \\ ${ }^{1}$ Assistant Divisional Medical Officer (Psychiatry), Department of psychiatry, Dr.B.A.M.Central railway \\ Hospital, Byculla, Mumbai \\ ${ }^{2}$ Senior Resident, ${ }^{3}$ Assistant professor, ${ }^{4}$ Professor Emeritus, Department of Psychiatry, T. N. Medical College \\ and B.Y.L. Nair Ch. Hospital, Mumbai, Maharashtra, India \\ Corresponding Author

\section{Dr Nitin Raut}

12, RB-IV, 5th floor, Doctor's Quarters,

Dr.B.A.M.Central railway Hospital, Byculla, Mumbai-400027

Email: talk2docni3@yahoo.co.in, Phone number: 9987645418

\begin{abstract}
Background: Loneliness is an important factor affecting mental well-being in elderly. The socio-demographic and health related factors determine feeling of loneliness in them.

Aims and Objectives: To study Socio-demographic and health related correlates of loneliness in elderly

Material and Methods: Cross sectional study done on 77 lonely and 22 non-lonely elderly were assessed clinically and using Geriatric Depression Scale-Short form [GDS-SF]and Loneliness Scale. Statistical analysis was done using SPSS-20 software.

Result: Depressive symptoms were associated with lonely group significantly $(t=9.776, p=.000)$. Unmarried, widowed and divorced status were more associated with loneliness (chi-square-8.160, p-0.043*). While other factors like female gender, history of self-harm, presence of stressors, divorced and widowed status, living without partner, having medical illness, poor perceived health, having alcohol and tobacco dependence, having subjective memory complains, impaired ADL(Activities of Daily Living) and presence of disability though not statistically significant but were more associated with lonely group. Social network related factors like number of social contacts and time spent in social activities were negatively associated with loneliness ( $t$-value =$2.304, p$-value-0.023*and $t$-value $=-2.290, p$-value-0.024*). Also on looking at the trend from normal $\rightarrow$ lonely $\rightarrow$ lonely and depressed both, the above variables as well as GDS scores showed decreasing trend. Meaning that change in these variables is associated with transition of person without loneliness and depression to having them gradually over a period of time in that order

Conclusion: Sociodemographic and health related factors are associated with feeling of loneliness in elderly. Number of social contacts and time spent in social activities significantly differ in normal, lonely and depressed elderly.
\end{abstract}

Keywords: elderly, loneliness, sociodemographic factors, health-related factors.

\section{Introduction}

The population aging is becoming a major concern for policy makers all over the world. The situation is no different in India where elderly population accounted for $7.1 \%$ of total population in 2001 and is projected to increase to $12.1 \%$ by 
$2026^{1}$. It is generally considered that the increasing numbers of elderly people, their changing status and changes in the nature of families and social networks in current society, will cause many problem ${ }^{2}$. Although Indian society had the traditional informal support systems such as joint family, kin and community but due to modernization and globalization, the capacity of the this support system is slowly weakening and is not in a position to fulfil even the basic needs of the elderly and they are left out as neglected and rejected members of the family. The traditional sense of responsibility of the younger generation towards their older generation is fading - all these have led to a miserable condition of elderly in the society causing number of psychological problems ${ }^{3}$. Loneliness in one of such important problems ${ }^{2}$.

Though loneliness has numerous definitions world-wide, in a way it has been defined as 'a discrepancy between one's desired and achieved levels of social relations ". This discrepancy is either in the number of relationships or the intimacy of the relationships ${ }^{5}$.It is frequently said that loneliness has emotional and social components where social loneliness refers to the absence of an adequate social network and acquaintances that can provide a sense of being a member of a community; whereas emotional loneliness refers to the absence of intimate attachments in one's life to turn to, when in need ${ }^{6}$. Recently a lot of research is being done on correlates of loneliness. Studies have found that various factors associated with loneliness are demographic factors like increased age and female gender, psychological factors, such as presence of depression and anxiety, presence of health conditions and problems. Interpersonal and social correlates of loneliness include loss of partner, reduced social activities, and an individual's poor evaluation of their neighbourhood. Some researchers also have studied correlates of social and emotional loneliness separately and found that that being female, absence of partner, being widowed, limited contact with children and relatives, being a caregiver, low self-esteem, and low income are more highly correlated with emotional than social loneliness; while being male, living in a rural set-ting, few social contacts, small network size, lack of instrumental and emotional network support, and poor health are more highly correlated with social than emotional loneliness ${ }^{5}$.

Loneliness is common in older people and is associated with adverse health consequences both from a mental and physical health point of view. It has been linked to a variety of problems like depressive symptoms, increased alcohol consumption, and increased vulnerability to many physical illnesses ${ }^{7}$.It has also been found to lower the quality of life in elderly ${ }^{8}$.

Thus apart from being the probable predictor of depression ${ }^{6}$,loneliness also seems to be an independent psychological factors in elderly population affecting their physical, mental as well as over-all well-being. Like other problems of the aged loneliness as well differs, not only between nations but also between various age groups ${ }^{9}$.Considering this our study strives to assess various socio-demographic as well as health related variables in elderly in urban India.

\section{Aims and Objective}

1. To study sociodemographic and health related variables in lonely and non-lonely elderly.

2. To compare sociodemographic and health related variables in lonely and non-lonely elderly.

\section{Material and Methods}

A] Study Design:

A cross sectional study was performed

\section{B] Ethics Committee:}

The study was carried out after due approval by the Institutional Ethics committee. A written informed consent was taken from the subjects before commencing the study. 
C] Site:

The study was conducted in the geriatric outpatient clinic of tertiary teaching municipal medical institute in Mumbai

\section{D] Subjects:}

99 elderly subjects visiting the geriatric outpatient psychiatry clinic in a tertiary teaching municipal medical institute in Mumbai.

\section{Lonely group -}

This group included 77 patients

\section{Inclusion Criteria -}

1. Patients with age of 60 years or more

2. Patients having significant scores on loneliness scale(three or more)

\section{Exclusion Criteria -}

1. Patients having any other present or past psychiatric illness other than depression

2. Patients having uncontrolled medical or surgical diseases

3. Patients not giving consent for the study

\section{Non-lonely}

Non-lonely group included 22 patients

\section{Inclusion Criteria -}

1. Patients with age of 60 years or more

2. Patients not a known case of any psychiatric illness

\section{Exclusion Criteria -}

1. Patients having uncontrolled medical or surgical diseases

2. Patients not giving consent for the study

\section{Scales}

1. Semi-structured proforma- for demographic and other details

2. Loneliness Scale- (De Jong Gierveld and Van Tilburg). It is an 11 items scale. The responses include ("more or less", "yes", or "no!"). It has some positive and negative item. The loneliness scale ranges from 0 (non-lonely) to 11 (extremely lonely) $(\alpha=.84)$. The scale has proved to be a reliable and valid instrument. The scale has two subscales (one for emotional loneliness and one for social loneliness, with $\alpha=.88$ and $\alpha=.88$, respectively). The cut-off scores of 3 is used to distinguish between lonely and non-lonely people $^{10}$.

3. Geriatric Depression Scale (GDS) short form, first created by Yesavage et al, has been tested and used extensively with the older population. Of the 15 items present, 10 indicated the presence of depression when answered positively, while the rest (question numbers 1, 5, 7, 11, 13) indicated depression when answered negatively. Scores of 0-4 are considered normal, 5-8 indicate mild depression; 9-11 indicate moderate depression; and 12-15 indicate severe depression. The GDS was found to have $92 \%$ sensitivity and a $89 \%$ specificity. The validity and reliability of the tool have been supported through both clinical practice and research ${ }^{11-12}$.

\section{Statistical Analysis}

1. SPSS version 20 was used to statistically analyze the data obtained.

2. Descriptive methods were used to study the demographical variables and frequency of other variables. Then inferential statistics was used to further analyze the data.

3. Independent sample $t$ tests were done to compute the statistical difference in the dependent variables among those who were lonely and non-lonely.

4. Cross tabulation and chi-square test was used compare qualitative variables between different groups.

5. ANOVA with post-hoc tests for multiple comparisons with scheffe's correction was used to compare various quantitative variables in different groups.

\section{Results}

The sociodemographic, other health related and individual related social variables of the sample are as given in the table 1 . 
The mean of age in the lonely and non-lonely group was 66.45 and 65.35.As social network and level of education are important component affecting psychological health in elderly, we also studied number of social contacts and time spent in these activities and other hobbies per week. These factors have been shown in table 2 .

For measuring Loneliness, the Loneliness Scale by De Jong Gierveld was used. Results showed that the mean Loneliness scores of patients in lonely group was higher than the patients who were non-lonely as expected, and this difference was tested to be statistically significant $(\mathrm{t}=16.88$, $\mathrm{p}=.000$ ). Difference was also significant on both Emotional as well as Social subscales in the two groups $(\mathrm{t}=16.450, \mathrm{p}=.000 \& \mathrm{t}=11.528, \mathrm{p}=.000$ respectively). (Table 3 )

Geriatric Depression Scale was used to study the severity of depression in two groups. Results showed that the mean GDS score of lonely patients was higher than the mean GDS score of patients who were non-lonely, as expected, and this difference was tested to be statistically significant $(\mathrm{t}=9.776, \mathrm{p}=.000)$. ( Table 4)

Further cross tabulation and Chi-square test was used to find association of qualitative variables under study with loneliness. Among the studied variables only marital status was significantly associated with loneliness (chi-square-8.160, p$\left.0.043^{*}\right)$, while other factors like female gender, other factors though not significantly but varied in the two groups. For example history of self-harm, presence of stressors, divorced and widowed status, living without partner, having medical illness, poor perceived health, having alcohol and tobacco dependence, having subjective memory complains, impaired ADL and presence of disability though not statistically significant but was more associated with lonely group.

In marital status on further analysing the difference it was found that Unmarried, widowed and divorced status was more associated with loneliness. (Table 5, Graph 1)

Further the quantitative variables were tested for difference in lonely and non-lonely group, on which we found that number of social contacts and time spent in social activities was significantly more in non-lonely group than lonely group $\left(\mathrm{t}\right.$-value $=-2.304, \mathrm{p}$-value- $0.023 *_{-}$and $\mathrm{t}$ value $=--2.290, \quad \mathrm{p}$-value-0.024*) respectively, meaning they are significantly negatively associated with loneliness. (Table 6)

Correlation was also done to find out association between the quantitative variables in the sample, which showed that number of social contacts were negatively associated with loneliness (emotional, social as well as total scores) and hours spent in social activities were negatively associated with emotional and total loneliness scores. (Table 7)

For further analysis of correlates of loneliness, the data was taken as divided into four groups on the basis of presence or absence Clinical depression, Cut off scores for GDS and Loneliness scale as shown below. After which groups were divided as Group N (22.2\%) in which subjects did not had significant score on GDS, loneliness scale or clinical diagnostic criterion. Group L (17.2\%) had significant scores only on loneliness scale and not the rest of them. Group GL (14.1\%) had significant scores on GDS as well as loneliness but did not fulfil clinical criterion, and the fourth group had all of them positive Group CGL (46.5\%). (Here after referred by these names).

On studying the all sociodemographic and healthrelated qualitative variables only gender was associated with loneliness significantly (more so female gender in CGL group).Other factors though not significantly but varied in the emerged groups. For example divorced and widowed status as well as not living with partner condition was more common in CGL group. Also history of selfharm, presence of stressors, divorced and widowed status, living without partner, having medical illness, poor perceived health, having alcohol and tobacco dependence, having subjective memory complains, impaired ADL and presence of disability though not statistically significant but was more associated with CGL group. (Graph 2-3)

On comparing the various quantitative variables in the four emerged groups by ANOVA we found that the difference was significant for hours spent 
in social activities, number of social contacts, and GDS scores (Table 8). While for years of education it was not found to be significant. On doing the post-hoc tests for multiple comparisons the number of social contact and hours spent in social activities differed in CGL and $\mathrm{N}$ group significantly. (p-0.044 and p-0.017)(Table 9).Also on looking at the trend from $\mathrm{N} \rightarrow \mathrm{GL}$ both the above variables as well as GDS scores showed decreasing trend. Meaning that these variables are associated in transition of person without loneliness and depression to having them gradually over a period of time.

Table 1: Sociodemographic, health related and individual related variables of sample

\begin{tabular}{|c|c|c|}
\hline & $\begin{array}{l}\text { Lonely } \\
\mathrm{N}(\%)\end{array}$ & $\begin{array}{l}\text { Non-lonely } \\
\mathrm{N}(\%)\end{array}$ \\
\hline \multicolumn{3}{|l|}{ 1. SEX } \\
\hline Females & $43(55.8)$ & $15(68.2)$ \\
\hline Males & $34(44.2)$ & $7(31.8)$ \\
\hline \multicolumn{3}{|c|}{ 2. MARITAL STATUS } \\
\hline Married & $48(62.3)$ & $13(59.1)$ \\
\hline Widowed/Widower & $24(31.2)$ & $5(18.2)$ \\
\hline Unmarried & $2(2.6)$ & $4(22.7)$ \\
\hline Divorced & $3(3.9)$ & $0(0)$ \\
\hline \multicolumn{3}{|l|}{ 3. FAMILY TYPE } \\
\hline Joint & $27(35.1)$ & $7(31.8)$ \\
\hline Nuclear & $50(64.9)$ & $15(68.2)$ \\
\hline \multicolumn{3}{|c|}{ 5.LIVING CONDITION } \\
\hline With partner & $46(59.7)$ & $13(59.1)$ \\
\hline Without partner & $31(40.3)$ & 11(40.9) \\
\hline \multicolumn{3}{|c|}{ 6.FINANCIAL DDsDEDEPENDENCE } \\
\hline Self & $33(42.9)$ & $10(45.5)$ \\
\hline \multicolumn{3}{|l|}{ 7.STRESSORS } \\
\hline Present & $23(29.9)$ & $3(13.6)$ \\
\hline Absent & $54(70.1)$ & $19(86.4)$ \\
\hline \multicolumn{3}{|c|}{ 8.CHRONIC MEDICAL ILLNESS } \\
\hline Present & $33(42.9)$ & $11(50)$ \\
\hline Absent & $44(57.1)$ & $11(50)$ \\
\hline \multicolumn{3}{|c|}{ 9.HISTORY OF SELF HARM } \\
\hline Yes & $6(7.8)$ & $0(0)$ \\
\hline No & $71(92.2)$ & $22(100)$ \\
\hline \multicolumn{3}{|c|}{ 11.SUBSTANCE DEPENDENCE } \\
\hline Alcohol & $7(9.1)$ & $0(0)$ \\
\hline Tobacco & $10(13)$ & $2(9.1)$ \\
\hline Both & $1(1.3)$ & $0(0)$ \\
\hline None & $59(66.6)$ & 20(90.9) \\
\hline \multicolumn{3}{|l|}{ 12.DISABILITY } \\
\hline Present & $8(10.4)$ & $1(4.5)$ \\
\hline Absent & $69(89.6)$ & $21(95.5)$ \\
\hline \multicolumn{3}{|c|}{ 13.SUBJECTIVE MEMORY COMPLAINS } \\
\hline Present & $15(19.5)$ & $2(19.1)$ \\
\hline Absent & $62(80.5)$ & 20(90.9) \\
\hline \multicolumn{3}{|l|}{ 14.ADL } \\
\hline Affected & $8(10.4)$ & $2(9.1)$ \\
\hline Unaffected & $69(89.6)$ & 20(90.9) \\
\hline \multicolumn{3}{|c|}{ 15.PERCEIVED HEALTH } \\
\hline Ok & $54(70.1)$ & $18(81.8)$ \\
\hline Poor & $23(29.9)$ & $4(19.2)$ \\
\hline
\end{tabular}


Table 2: showing details of social network related and individual related variables of sample

\begin{tabular}{|c|c|c|c|}
\hline & GROUP & $\mathrm{N}$ & MEAN \\
\hline \multirow[t]{2}{*}{ AGE } & Lonely & 77 & 66.45 \\
\hline & Non-lonely & 22 & 65.32 \\
\hline \multirow[t]{2}{*}{ YEARS OF EDUCATION } & Lonely & 77 & 6.03 \\
\hline & Non-lonely & 22 & 6.41 \\
\hline \multirow[t]{2}{*}{ NUMBER OF SOCIAL CONTACTS } & Lonely & 77 & 2.53 \\
\hline & Non-lonely & 22 & 5.18 \\
\hline \multirow{2}{*}{$\begin{array}{l}\text { HOURS SPEN IN HOBBIES/SOCIAL } \\
\text { ACTIVITIES PER WK }\end{array}$} & Lonely & 77 & 4.86 \\
\hline & Non-lonely & 22 & 7.73 \\
\hline
\end{tabular}

Table 3: Shows the difference in Loneliness scores between those who were lonely and non-lonely

\begin{tabular}{|l|c|c|c|}
\hline LONELINESS SCALE & Mean & t value & p value \\
\hline $\begin{array}{l}\text { LONELY } \\
\text { (EMOTIONAL) }\end{array}$ & 4.05 & 16.450 & $.000^{*}$ \\
\hline NON-LONELY (EMOTIONAL) & .64 & 11.528 & $.000^{*}$ \\
\hline LONELY (SOCIAL) & 2.96 & & \\
\hline NON-LONELY (SOCIAL) & 7.01 & 16.883 & $.000^{*}$ \\
\hline $\begin{array}{l}\text { LONELY (TOTAL } \\
\text { TOTAL LONELINESS ) }\end{array}$ & 1.50 & & \\
\hline $\begin{array}{l}\text { NON-LONELY } \\
\text { LONELINESS ) }\end{array}$ & & \\
\hline
\end{tabular}

$* \mathrm{p}<0.01$

Table 4: Shows the difference in GDS scores between those who were lonely and non-lonely

\begin{tabular}{|l|l|l|l|}
\hline GDS & \multicolumn{1}{|c|}{ Mean } & t value & p value \\
\hline Lonely & 7.36 & & \\
\hline Non-lonely & & 9.776 & $.000^{*}$ \\
\hline$* p<0.01$ & 2.45 & & \\
\hline
\end{tabular}

Table 5: Showing Chi-square test comparing qualitative variables in lonely and non-lonely group

\begin{tabular}{|l|l|l|l|}
\hline & Pearson Chi-Square & Df (degrees of freedom) & p-value \\
\hline Gender & 1.074 & 1 & .300 \\
\hline Marital status & 8.160 & 3 & $.043^{*}$ \\
\hline Family type & .080 & 1 & .777 \\
\hline Living condition & .003 & 1 & .956 \\
\hline Financial dependence & .047 & 1 & .828 \\
\hline Medical illness & .354 & 1 & .552 \\
\hline Stressors & 2.329 & 1 & .127 \\
\hline Substance dependence & 2.938 & 3 & .401 \\
\hline History of self-harm & 1.825 & 1 & .177 \\
\hline Perceived health & 1.179 & 1 & .278 \\
\hline ADL & .032 & 1 & .859 \\
\hline Disability & .707 & 1 & .400 \\
\hline Subjective memory complains & 1.299 & 1 & .254 \\
\hline
\end{tabular}

$*=\mathrm{p}<0.05$ 
Table 6: Showing comparison of quantitative variables between lonely and non-lonely group

\begin{tabular}{|c|c|c|c|}
\hline & Mean & $\mathrm{t}$ value & $\mathrm{p}$ value \\
\hline $\begin{array}{l}\text { Lonely } \\
\text { (Age in years) }\end{array}$ & 66.45 & \multirow[t]{2}{*}{.854} & \multirow[t]{2}{*}{0.399} \\
\hline $\begin{array}{l}\text { Non-lonely } \\
\text { (Age in years) }\end{array}$ & 65.32 & & \\
\hline $\begin{array}{l}\text { Lonely } \\
\text { (No. of social contacts) }\end{array}$ & 2.53 & \multirow[b]{2}{*}{-2.304} & \multirow[b]{2}{*}{$0.023 *$} \\
\hline $\begin{array}{l}\text { Non-lonely } \\
\text { (No. of social contacts) }\end{array}$ & 5.18 & & \\
\hline $\begin{array}{l}\text { Lonely } \\
\text { (Time spent in social activities and hobbies) }\end{array}$ & 4.86 & \multirow{2}{*}{-2.290} & \multirow{2}{*}{$.024 *$} \\
\hline $\begin{array}{l}\text { Non-lonely } \\
\text { (Time spent in social activities and hobbies) }\end{array}$ & 7.73 & & \\
\hline $\begin{array}{l}\text { Lonely } \\
\text { (education years) }\end{array}$ & 6.03 & \multirow{2}{*}{-.367} & \multirow{2}{*}{.715 } \\
\hline Non-lonely $\quad$ (education years) & 6.41 & & \\
\hline
\end{tabular}

Table 7: Showing correlation between the quantitative variables in the sample

\begin{tabular}{|l|l|l|l|}
\hline Groups & No. of social contacts & $\begin{array}{l}\text { Hrs spent in social } \\
\text { activities per week }\end{array}$ & $\begin{array}{l}\text { GDS } \\
\text { scores }\end{array}$ \\
\hline Emotional loneliness & $-0.248^{* *}$ & $-0.236^{* *}$ & $0.812^{* *}$ \\
\hline Social loneliness & $-0.245^{* *}$ & -0.125 & $0.625^{* *}$ \\
\hline Total loneliness & $-0.268^{* *}$ & $-0.203^{* *}$ & $0.792^{* *}$ \\
\hline
\end{tabular}

**-Correlation is significant at 0.01 level

Table 8: Showing comparison of various quantitative variables in the 4 groups (ANOVA)

\begin{tabular}{|l|c|c|c|}
\hline & $\mathrm{df}$ & $\mathrm{F}$ & $\mathrm{p}$-value \\
\hline Age & 3 & 0.816 & .488 \\
\hline Yrs. of education & 3 & 0.653 & .583 \\
\hline No. of social contacts & 3 & 3.267 & $.025^{*}$ \\
\hline Hrs in social activities & 3 & 4.93 & $.003^{*}$ \\
\hline GDS scores & 3 & 101.823 & $.000^{* *}$ \\
\hline Emotional loneliness & 3 & 91.656 & $.000^{* *}$ \\
\hline Social loneliness & 3 & 17.223 & $.000^{* *}$ \\
\hline Total loneliness & 3 & 56.75 & $.000^{* *}$ \\
\hline
\end{tabular}

$*_{\text {-Correlation is significant at } 0.05 \text { level }}$

**-Correlation is significant at 0.01 level

Table 9: Showing post-hoc multiple comparisons of social network related factors in the four groups

\begin{tabular}{|l|l|c|c|c|c|}
\hline \multicolumn{2}{|l|}{} & & $\begin{array}{c}\text { Mean } \\
\text { Difference } \\
\text { (I-J) }\end{array}$ & $\begin{array}{c}\text { Std. } \\
\text { Error }\end{array}$ & Sig. \\
\hline Number of social contacts & \multirow{2}{*}{$3 \mathrm{CGL}$} & $4 \mathrm{GL}$ & -1.634 & 1.434 & .730 \\
\cline { 3 - 6 } & & $5 \mathrm{~L}$ & -2.642 & 1.334 & .277 \\
\cline { 3 - 6 } & & $6 \mathrm{~N}$ & $-3.530^{*}$ & 1.218 & $.044^{*}$ \\
\hline Hours spent in social activities & \multirow{3}{*}{$3 \mathrm{CGL}$} & $4 \mathrm{GL}$ & -2.736 & 1.527 & .366 \\
\cline { 3 - 7 } & & $5 \mathrm{~L}$ & -3.992 & 1.420 & .054 \\
\cline { 3 - 7 } & & $6 \mathrm{~N}$ & $-4.249^{*}$ & 1.297 & $.017^{*}$ \\
\hline
\end{tabular}

*-Correlation is significant at 0.05 level 


\section{JMSCR Vol||04||Issue||11||Page 13834-13846||November}

Graph 1: showing comparison of socio-demographic variables in lonely and non-lonely groups

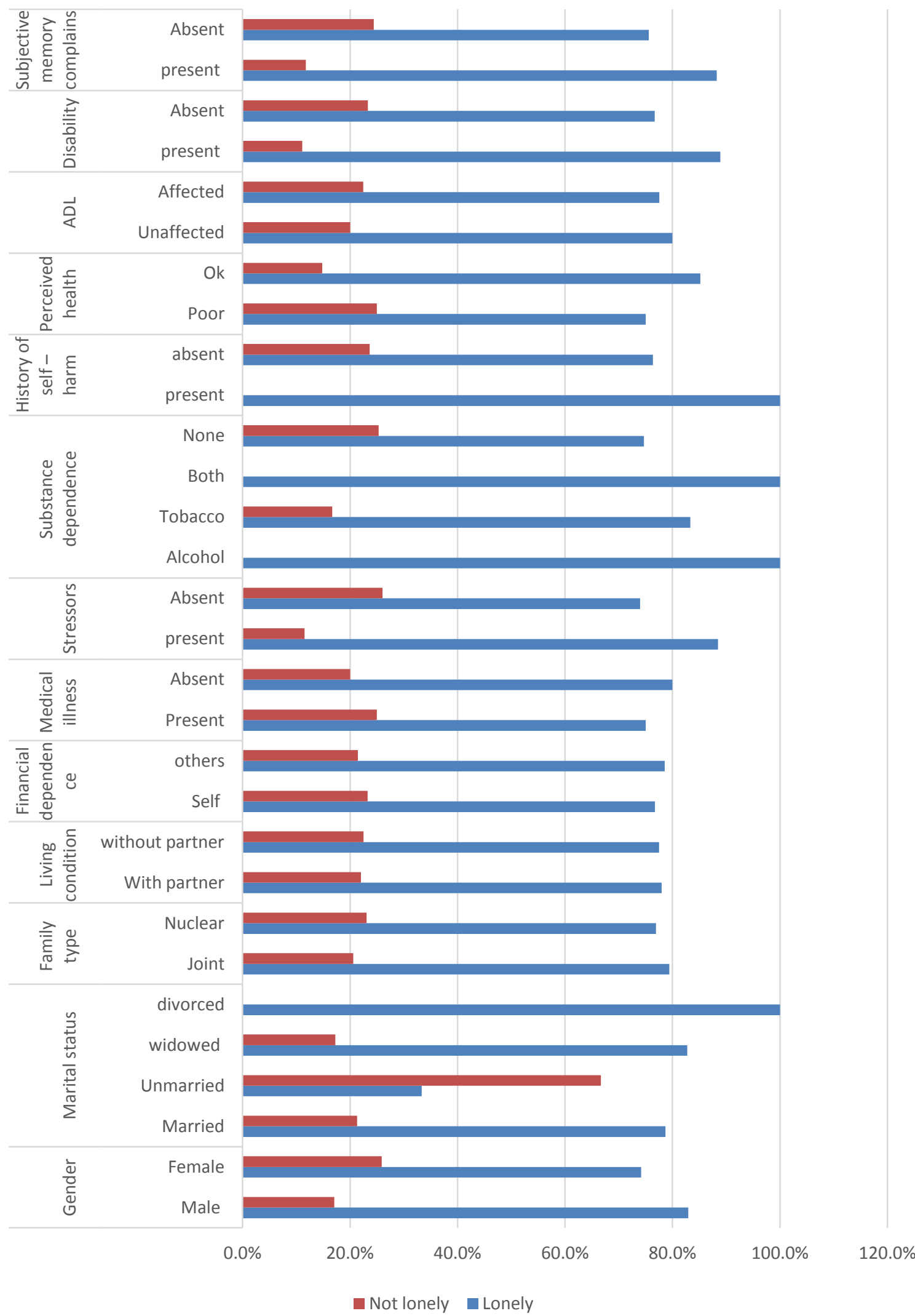


Graph 2: showing comparison of socio-demographic variables in 4 groups

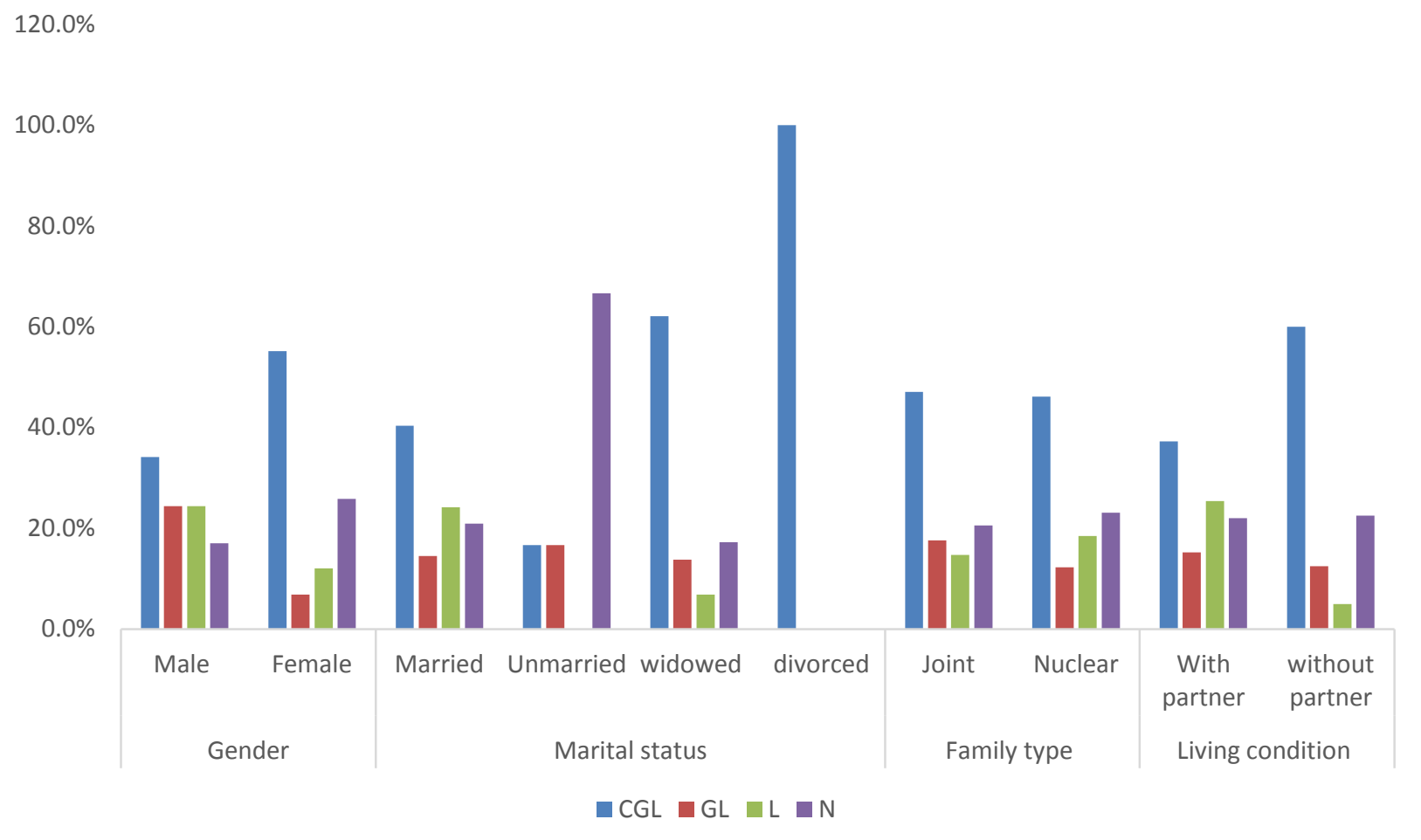

Graph 3: showing comparison of health-related and other variables in 4 groups

$120.0 \%$

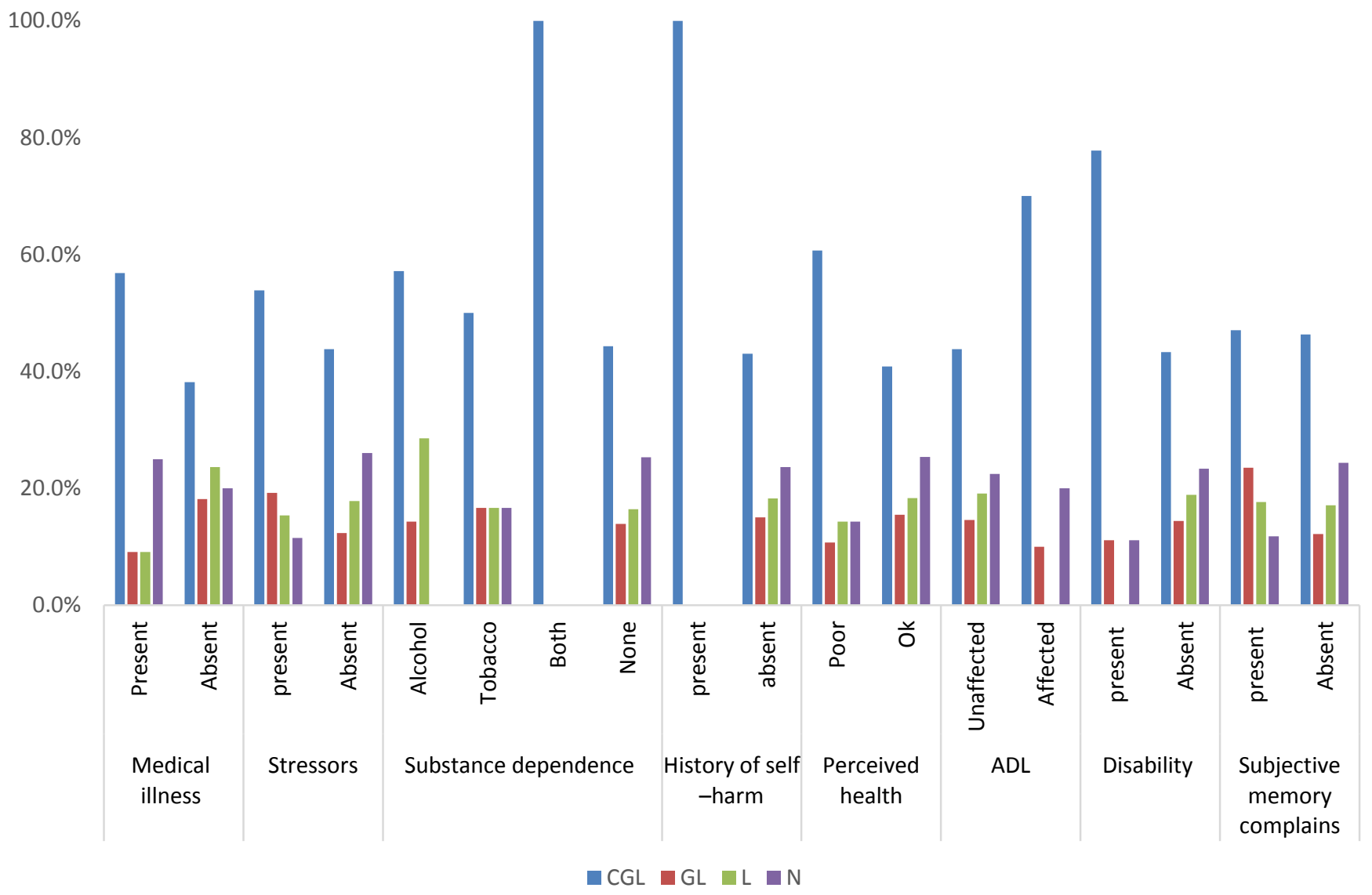


Graph 4: Showing comparison of various quantitative variables in the 4 groups

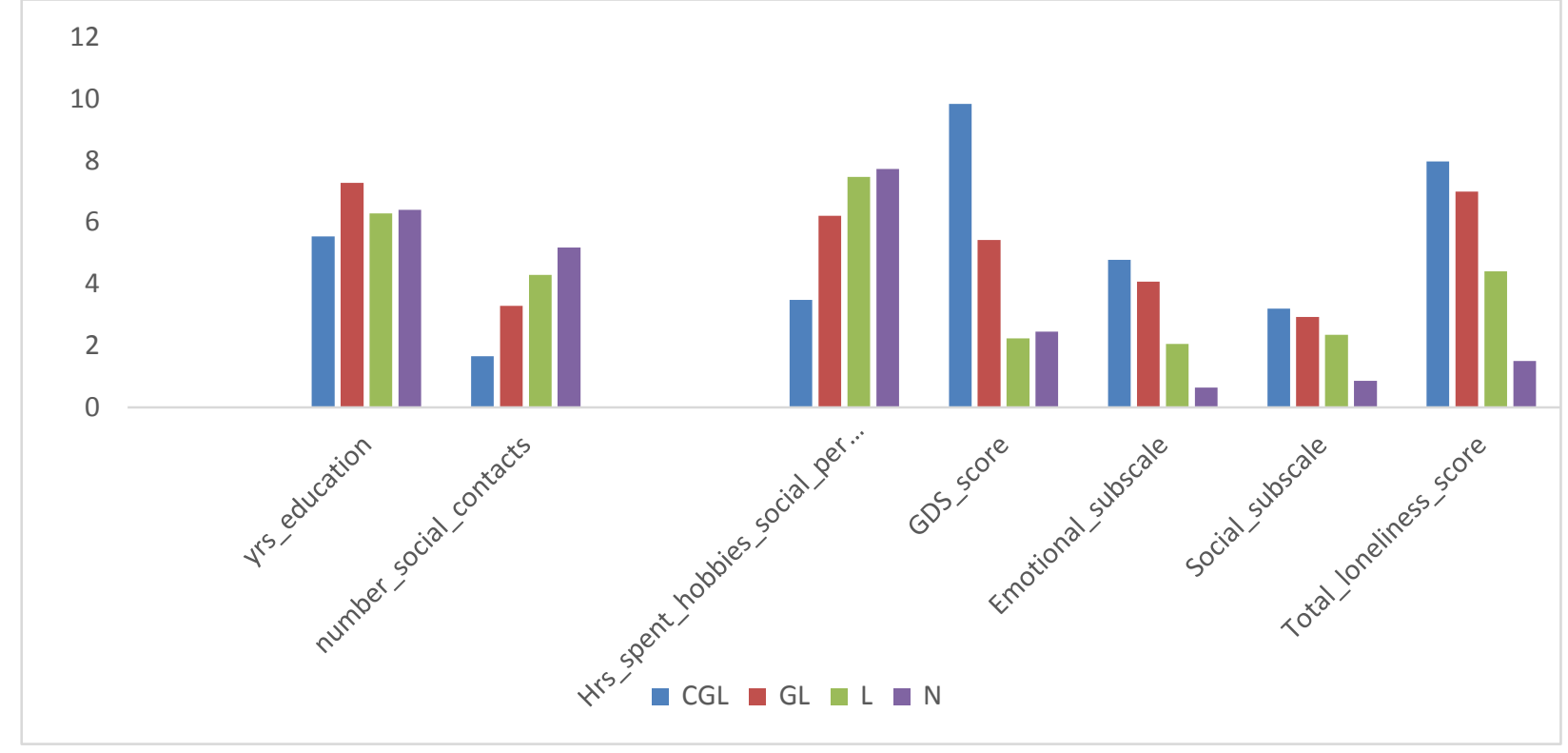

\section{Discussion}

Results of the study showed that that the mean Loneliness score of patients in lonely group was higher than the patients who were non-lonely as expected, and this difference was tested to be statistically significant the difference was also significant on both Emotional as well as Social subscales. This is consistent with the fact that Loneliness scale by De Jong Gierveld has proven ability to discriminate between lonely and nonlonely individuals and the two subscales are also moderately correlated with each other ${ }^{10}$.

Among the studied variables only marital status was significantly associated with loneliness, while other factors like history of self-harm, presence of stressors, divorced and widowed status, living without partner, having medical illness, poor perceived health, having alcohol and tobacco dependence, having subjective memory complains, impaired ADL and presence of disability though not statistically significant but were more associated with lonely group.

In marital status on further analysing the difference it was found that Unmarried, widowed and divorced status was more associated with loneliness. In a similar study it was found that married elderly people were feeling less lonely than single and widow elderly people.
Widowhood and the loss of a close friend are proven determinants of loneliness ${ }^{2}$. The results of other studies have also supported this findings ${ }^{13}$.However unlike our study they found that elderly living with their spouses or spouses and children had felt less loneliness. Further, they also found that impairment of physical functioning and poor health associated with impaired ADL, leads to dependency on the help of others in daily living, to staying at home and to an increased need for health care services, which were all associated with feelings of loneliness ${ }^{2}$.

Further the quantitative variables were tested for difference in lonely and non-lonely group, on which we found that number of social contacts and time spent in social activities was significantly more in non-lonely group than lonely group, meaning they are significantly negatively associated with loneliness. Correlation was also done to find out association between the quantitative variables in the sample, which showed that number of social contacts were negatively associated with loneliness (emotional, social as well as total scores) and hours spent in social activities were negatively associated with emotional and total loneliness scores.

A study assessing correlates of loneliness also reported Lack of a social network and having few 
social contacts $^{14}$ as clearly associated with loneliness. Elderly people who have limited social networks do not receive enough support and emotional $^{15}$. Further age related losses lead to loss of network, a person's incapability or unwillingness to create new social contacts and poor self-awareness and insecurity which may all lead to social isolation and loneliness ${ }^{2}$.

Further after dividing the lonely group into 3 groups, and comparing these three and non-lonely group ,out of all the sociodemographic qualitative variables only gender was associated with loneliness significantly (more so female gender in CGL group). Other factors though not significantly but varied in the emerged groups. For example divorced and widowed status as well as not living with partner condition was more common in CGL group. Studies in past have revealed mixed results till now. In a study examining the factors affecting the feeling of loneliness of the elderly, it was found that males had felt more loneliness as compared to females, but it was not statistically significant. According to some studies, males are more often lonely than female ${ }^{16-17}$, but other studies have reported results to the contrary ${ }^{2}$.

The mean scores on GDS and loneliness showed an increasing trend from L to CGL, indicating a presence of continuum with normality at one end and a combination of loneliness and depression at the other, through a distinct stage where only loneliness is present indicating it as a distinct concept, different from depression. On comparing the various quantitative variables in the four emerged groups by ANOVA we found that the difference was significant for hours spent in social activities, number of social contacts, and GDS scores. While for years of education it was not found to be significant. On doing the post-hoc tests for multiple comparisons the number of social contact and hours spent in social activities differed in CGL and $\mathrm{N}$ group significantly. Also on looking at the trend from $\mathrm{N} \rightarrow \mathrm{CGL}$ both the above variables as well as GDS scores showed decreasing trend. Meaning that change in these variables is associated with transition of person without loneliness and depression to having them gradually over a period of time in that order. So the $\mathrm{L} \rightarrow \mathrm{GL} \rightarrow \mathrm{CGL}$ path becomes imminent as person starts losing his social contacts and spends less time in these activities. As already discussed earlier social contact and time spent in social activities are associated negatively with loneliness. A study has found buffering effect of social network and contact on depressive symptoms ${ }^{18}$, probably that is the reason for the significant difference between the group having depression and normal group. Also as we know that due to multiple factors like presence of medical illness, disabilities, age related losses cause thinning of social network gradually, which subsequently leads to depression ${ }^{6}$.

\section{Conclusions}

Loneliness is an important psychological factor affecting mental health in elderly because of its association with depression as well as a unique entity itself. This study provides valuable insights into psychological, health, and social factors that are associated with loneliness. Our study found that:-

1. Depressive symptoms were associated with lonely group significantly

2. Unmarried, widowed and divorced status was more associated with loneliness. While other factors like female gender, history of self-harm, presence of stressors, divorced and widowed status, living without partner, having medical illness, poor perceived health, having alcohol and tobacco dependence, having subjective memory complains, impaired ADL and presence of disability though not statistically significant but were more associated with lonely group.

3. Social network related factors like number of social contacts and time spent in social activities was negatively associated with loneliness. 


\section{Implications}

Since loneliness is associated with deficient social network and less time in social activities, interventions aimed at managing these factors like like mutual help groups, friendship programs and other social interventions at early stage becomes necessary, which will help them to ward off loneliness and hence depression.

Many sociodemographic variables also are significantly associated with loneliness, clinicians need to look out for these factors while assessing elderly people with psychological problems, so that lonely individuals are identified early and intervention can be started to avoid progression to more severe outcomes.

\section{References}

1. Situation Analysis of the Elderly in India, Central Statistics Office Ministry of Statistics \& Programme Implementation. Government of India. June 2011.

2. Jones DA, Victor CR, Vetter NJ. The problem of loneliness in the elderly in the community: characteristics of those who are lonely and the factors related to loneliness. R Coll Gen Pract. 1985 March; 35(272): 136-139.

3. Singh S, Raut NB, Subramanyam AA, Kamath R, Pinto C, Shanker S. Perception of old age and self: A comparative study of elderly females living in community and in old age homes. J Geriatr Ment Health 2014; 1:32-7.

4. Peplau LA., Perlman D. Perspectives on loneliness. In L. A. Peplau \& D. Perlman (Eds.), Loneliness: A Sourcebook of Current Theory, Research and Therapy (pp. 1-20). 1982. New York: John Wiley $\&$ Sons.

5. Dahlberg L, Kevin JM. "Correlates of social and emotional loneliness in older people: evidence from an English community study." Aging Ment Health.2014; 18.4: 504-514.
6. Raut NB,Singh S, Subramanyam AA., Pinto C, Kamath RM,Shanker S. Study of loneliness, depression and coping mechanisms in elderly. Journal of J Geriatr Ment Health 2014; 1: 20-27.

7. Cervinkova M, Muhumad K.Effect of loneliness on elderly people's lives. A dissertation submitted to Tampere University of applied sciences (2011).

8. Cacioppo JT, Hughes ME, Waite LJ, Hawkley LC, Thisted RA. Loneliness as a specific risk factor for depressive symptoms: cross-sectional and longitudinal analyses. Psychol aging. 2006; 21(1): 140.

9. Bhatia S, Swami H M, Thakur J S, Bhatia V. A study of health problems and loneliness among the elderly in Chandigarh. Indian $\mathrm{J}$ Community Med 2007; 32:255-8.

10. De Jong Gierveld, J, Van Tilburg T. Manual of the Loneliness Scale .1999. Department of Social Research Methodology, Vrije Universiteit Amsterdam, Amsterdam (updated version 18.01. 02).

11. Sheikh JI, Yesavage JA. Geriatric Depression Scale (GDS). Recent evidence and development of a shorter version. In T.L. Brink (Ed.), Clinical Gerontology: A Guide to Assessment and Intervention.1986. (pp. 165-173). NY: The Haworth Press, Inc.

12. Yesavage JA., Brink TL, Rose TL, Lum O, Huang V, Adey MB et al. Development and validation of a geriatric depression screening scale: A preliminary report. J Psychiatr Res 1983; 17:37-49.

13. Kivett VR.Discriminations of loneliness among the rural elderly: implications for intervention. Gerontol 1979; 19: 108-115.

14. Mullins IC, Dugan E.The influence of depression, and family, friends and relations, on residients' loneliness in 
congregate housing. Gerontol 1990; 30: 377-384.

15. Bondevik, M., \& Skogstad, A.The oldest old, ADL, social network, and loneliness. West J Nurs Res 1998; 20: 325-343.

16. Andersson, L, Stevens N. Associations between early experiences with parents and well-being in old age. J Gerontol 1993; 48:109-116.

17. Chang SH., Yang MS. The relationships between the elderly: loneliness and its factors of personal attributes, perceived health status and social support. Kaohsiung J Med Sci 1999; 15:337-347.

18. Sicotte M, Alvarado BE, León EM.,Zunzunegui MV.Social networks and depressive symptoms among elderly women and men in Havana, Cuba. Aging and Mental Health, 2008; 12(2):193-201 